\title{
Um estudo empírico sobre a gestão do conhecimento em uma empresa fabricante de equipamentos elétricos
}

\section{RESUMO}

O presente artigo destaca a importância da aquisição contínua de novos conhecimentos na busca da competitividade e inovação nas organizações. Nesse contexto, tem como objetivo caracterizar a Gestão do Conhecimento (GC) em uma grande empresa da região norte do estado de Santa Catarina, na cidade de Jaraguá do Sul. Para a coleta de dados, utilizou-se um questionário, que faz parte de um levantamento global cuja finalidade foi de realizar uma revisão do estado atual das atividades e do progresso da GC no âmbito da pesquisa acadêmica e da prática organizacional. Os resultados encontrados permitiram identificar que existem desafios e necessidades de pesquisas futuras em GC, na empresa pesquisada.

Palavras-chave: Equipamentos elétricos. Tecnologia. Gestão do conhecimento.

Isabela Regina Fornari Müller isabela.esag@gmail.com Mestre em Administração. Universidade do Estado de Santa Catarina

Emílio da Silva Neto emilio@arcoirisalimentos.com.br Mestre em Engenharia Mecânica. Universidade Federal de Santa Catarina

Pierry Teza pierry.teza@gmail.com Mestre em Engenharia de Produção. Instituto Federal de Santa Catarina

Lucas Novelino Abdala lucasemc@gmail.com Mestre em Engenharia Mecânica. Universidade Federal de Santa Catarina 


\section{INTRODUÇÃO}

Para superar os grandes desafios da atualidade, as empresas precisam desenvolver uma estratégia de competitividade para continuarem crescendo de maneira sustentável.

Um dos meios consiste na adequada gestão do conhecimento, não só daquele acumulado e disseminado ao longo da sua existência organizacional, como também, e principalmente, daquele ainda implícito (tácito), de posse individual de seus integrantes, não explicitado, não compartilhado horizontalmente com toda a equipe.

O fato é que a competição e a evolução tecnológica tornaram o conhecimento e o tempo importantes diferenciais competitivos para as empresas. O ciclo de vida dos produtos, graças aos crescentes investimentos em pesquisa e desenvolvimento, está sendo reduzido drasticamente. Copiar produtos da concorrência já não é mais um investimento de retorno aceitável. Assim, o binômio conhecimento + tempo passou a ser um fator determinante para o sucesso ou o fracasso de uma empresa; quer dizer, naquilo que se convencionou chamar de sociedade ou economia do conhecimento, o conhecimento organizacional passou a ser o seu ativo mais importante, ainda que muitas vezes não contabilizado nos sistemas de informação econômico-financeiros tradicionais.

Esse conhecimento organizacional, resultado de uma combinação de pessoas (suas competências e relacionamentos), tecnologias (suas funcionalidades e interfaces) e processos (sistemas de produção e de gestão) é, atualmente, o principal fator de produção, de agregação de valor, de produtividade e de crescimento das empresas.

\section{FUNDAMENTAÇÃO TEÓRICA}

A literatura, já consolidada, tem demonstrado a importância do conhecimento para as organizações da atualidade (NONAKA; TAKEUCHI, 1997; DAVENPORT; PRUSAK, 2003). Davenport e Prusak (2003, p. 20) afirmam que "a vantagem do conhecimento é sustentável, porque gera retornos crescentes e dianteiras continuadas".

No entendimento de Freire et al. (2012), todas as organizações utilizam e geram conhecimentos no decorrer de seus processos, consistindo num conjunto de tarefas específicas, desenvolvidas no meio organizacional. E à medida que essas organizações detêm mais conhecimento, tendem a serem bem-sucedidas.

\subsection{Gestão do Conhecimento}

De acordo com Uriarte Jr. (2008), não há uma definição universalmente aceita para a GC, mas, de uma forma simples, ela pode ser tomada como a conversão do conhecimento tácito em conhecimento explícito, e seu respectivo compartilhamento dentro da organização. Ainda, segundo o autor, de modo mais preciso, GC é o processo por meio do qual as organizações geram valor de seus ativos intelectuais baseados em conhecimento. Atualmente, existem vários conceitos de GC publicados. Kimiz (2005), realizando uma pesquisa, identificou mais de cem definições, dentre as quais se destaca a definição de Sun e Hao (2006) citados por Steil (2007, p. 4, tradução nossa): "GC é a criação de processos de gestão e infraestrutura para trazer conhecimento e comunicações juntas em uma ecologia comum que deve apoiar a criação, utilização e retenção de conhecimento". Complementarmente, Uriarte Jr. (2008) explica que a GC está relacionada com o processo de identificação, aquisição, distribuição e manutenção do conhecimento, que é essencial para a organização.

No entendimento de Nogueira (2013), a GC consiste em um processo de transformação de conhecimento em um ativo organizacional de valor, sendo necessária a sua formalização, disseminação, compartilhamento e aplicação.

A GC também pode ser vista nas três perspectivas classificadas por Kimiz (2005), que tomou por base alguns conceitos pesquisados (Quadro 1). 
Quadro 1 - Perspectivas da Gestão de Conhecimento

\begin{tabular}{|c|l|}
\hline $\begin{array}{c}\text { Perspectivas de } \\
\text { Negócios }\end{array}$ & $\begin{array}{l}\text { A GC é uma atividade de negócio, que trata o conhecimento como } \\
\text { um componente das atividades do negócio que reflete a estratégia, a } \\
\text { política e prática em todos os níveis da organização, assim como aborda } \\
\text { de maneira colaborativa e integrada a criação, captura, organização, } \\
\text { acesso e utilização dos ativos intelectuais de uma empresa. }\end{array}$ \\
\hline $\begin{array}{c}\text { Ciência Cognitiva ou } \\
\begin{array}{c}\text { Perspectiva da Ciência } \\
\text { do Conhecimento }\end{array}\end{array}$ & $\begin{array}{l}\text { Entende o Conhecimento como sendo as percepções, os entendimentos } \\
\text { e o saber-fazer" que faz o indivíduo agir de modo inteligente, e que } \\
\text { pode ser transformado em livros, tecnologias, práticas e tradições } \\
\text { dentro de qualquer empresa e na sociedade. }\end{array}$ \\
\hline $\begin{array}{c}\text { Perspectiva do Processo } \\
\text { ou Tecnologia }\end{array}$ & $\begin{array}{l}\text { A GC propicia a transformação da informação em conhecimento } \\
\text { acessível e disponível para uso e aplicação. }\end{array}$ \\
\hline
\end{tabular}

Fonte: Adaptado de Kimiz (2005, p. 4-5)

Wiig (1993), citado por Kimiz (2005), considera que as organizações terão um maior sucesso quando tiverem à sua disposição o melhor conhecimento, pois poderão saber melhor o que e como fazer, uma vez que o conhecimento é a principal força que determina e dirige a capacidade de agir.

Campos, Langres e Lemos (2014) salientam que a GC é crucial a ser trabalhada nas empresas que querem prosperar no mercado mundial. Isso porque é por meio do crescimento de cada um que faz parte da organização, bem como de todos os seus integrantes como grupo, que ela poderá apresentar crescimento sustentável.

Dubois e Wilkerson (2008) apresentam quatro elementos da GC: natureza da cultura organizacional; processos usados para coletar, gerir e disseminar informação; condições e disponibilidade do conteúdo da organização e infraestrutura de tecnologia. As autoras afirmam que, uma vez que os elementos são endereçados e coordenados de uma maneira estratégica, o resultado é muitas vezes referido como um Sistema de GC. Porém, elas complementam mencionando que, além dos elementos, um Sistema de GC deve ser flexível e orientado pelo contexto, dado que o conhecimento é orgânico. Complementarmente, as autoras salientam o papel das pessoas nos quatro elementos citados, especialmente no que diz respeito ao conhecimento tácito.

Com relação à cultura organizacional, Dubois e Wilkerson (2008) afirmam que ela pode ser definida como um meio de perceber, pensar e sentir, compartilhar e transmitir entre membros organizacionais. Com base em DeTienne et al. (2004), citados por Dubois e Wilkerson (2008), as autoras ressaltam que uma cultura organizacional para a GC consiste em normas e práticas que promovem o fluxo livre de informação entre empregados, por meio dos departamentos. Além disso, três componentes são essenciais para criar culturas propícias para a gestão do conhecimento: um ou mais meios efetivos para aumentar o envolvimento cooperativo e alavancar o conhecimento dentro de departamentos particulares, e participar em comunidades de prática; interações face a face, que aumentam o conhecimento baseado em confiança; incentivos que podem ser tangíveis ou intangíveis, grandes ou pequenos.

No que tange ao conteúdo, Dubois e Wilkerson (2008) asseveram que esse é o conhecimento a ser gerenciado, ou seja, dados, informação, habilidades e expertise. As autoras ainda afirmam que muitas vezes as organizações criam conteúdo sem procedimentos para tornar as informações acessíveis para toda a organização. Dubois e Wilkerson (2008) complementam mencionando que o conhecimento a ser identificado e compartilhado pode ser tanto conhecimento explícito quanto tácito.

Segundo Dubois e Wilkerson (2008), processos são vitais ao sucesso da GC.

"Processos de GC são as atividades ou iniciativas que você colocou no lugar de permitir
e facilitar a criação, compartilhamento e uso do conhecimento para o benefício de sua
organização. Processos também se referem à infraestrutura geral de sua organização e
às formas de fazer as coisas e na medida em que estes atuam como facilitadores de, ou
barreiras para, a boa prática KM" (NATIONAL HEALTH SERVICE, 2005, p. 57 apud DUBOIS;
WILKERSON, 2008, p. 26).

Dubois e Wilkerson (2008) iniciam tratando da tecnologia afirmando que frequentemente ela é considerada um componente importante, e é responsável por $25 \%$ do sucesso da estratégia de GC.

Segundo as autoras, tecnologia é importante porque possibilita fácil acesso às necessidades em relação ao conhecimento e, nesse sentido, a tecnologia é a chave para o gerenciamento do conteúdo. No entanto, Dubois e Wilkerson (2008) esclarecem que nenhum produto de tecnologia atende a todos os requisitos necessários e que, antes de selecionar uma solução, as organizações precisam 
definir claramente sua estratégia de GC, o escopo e os requisitos. As organizações devem igualmente avaliar produtos de tecnologia disponíveis para identificar os que atendam às suas necessidades.

Finalmente, no que se relaciona às pessoas, Dubois e Wilkerson (2008) comparam-nas a um fio essencial que corre ao longo dos quatro componentes da GC. Nesse sentido, as autoras explicam que esforços de capacitação são essenciais para o sucesso da GC. Uma organização só aprende quando um indivíduo é capaz de transmitir a compreensão ou alterar o comportamento da organização (THELEN, 2004 apud DUBOIS; WILKERSON, 2008). Relacionando os quatro elementos referentes às pessoas, as autoras lembram que essencialmente, dentro de uma estratégia de GC, são as pessoas que moldam a cultura, entregam o processo, gerenciam o conteúdo e trabalham com a tecnologia.

\subsection{Diagnóstico de Gestão do Conhecimento}

O manual publicado pela Asian Productivity Organization (NAIR; PRAKASH, 2009) apresenta um questionário para ajudar as organizações a reconhecerem e avaliarem seus pontos fortes e oportunidades de melhorias a fim de concentrarem seus programas de GC nas lacunas identificadas. Sob o formato de guia, ele está baseado em um framework de GC (Figura 1) derivado de um trabalho encomendado pela Asian Productivity Organization (APO).

O framework apresentado foi desenvolvido, segundo Nair e Prakash (2009), com base na experiência prática em GC de vários países da Ásia, bem como dos EUA, Austrália e Europa; é de fácil implementação e, mais especificamente, ao contexto asiático. Os autores salientam que o objetivo do framework é fornecer um entendimento comum entre os países membros e enfatizar o valor da GC para o sucesso organizacional. De acordo com Nair e Prakash (2009), a estrutura é simples e abrangente, aborda todos os elementos relevantes de uma solução de GC e serve como uma referência para todos os tipos de organização, com o objetivo de melhorar o desempenho por meio da GC. Especificamente o guia tem como objetivo fornecer informações para a implantação da GC.

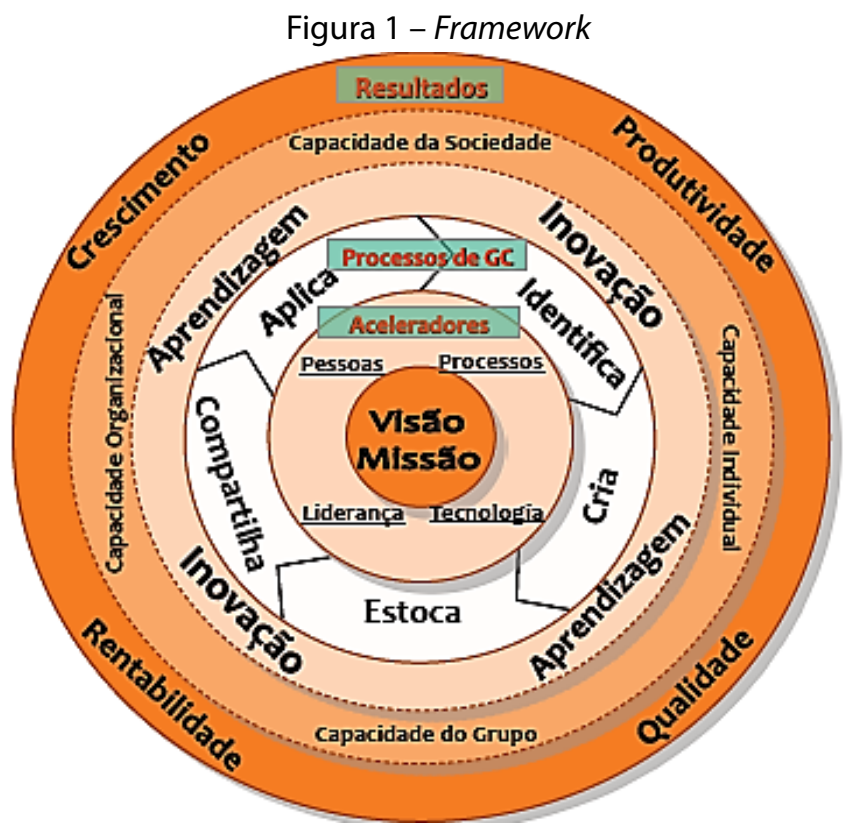

Fonte: Adaptado de Nair e Prakash (2009)

O framework tem seu ponto inicial que é a identificação e análise das competências essenciais e capacidades, com o entendimento da visão organizacional, missão, os objetivos de negócio e estratégica. A Análise dos aceleradores (pessoas, processos, tecnologia, liderança) permite uma implementação da GC. Os processos de conhecimento (identifica, cria, estoca, compartilha e aplica) permitem avaliar as práticas existentes de GC. O resultado final da aplicação do framework deve ser capaz de apresentar a melhoria da aprendizagem e inovação para a capacitação das equipes, indivíduos, organização e sociedade, agregando valor e qualidade aos produtos e serviços, gerando lucro e crescimento.

\section{ABORDAGEM METODOLÓGICA}


É importante destacar que, apesar de o tema gestão do conhecimento ser estudado na literatura internacional há mais de vinte anos, as pesquisas empíricas ainda são relativamente escassas. Nesse sentido, este artigo procura trazer uma contribuição empírica à área. A pesquisa realizada caracteriza-se como exploratória e descritiva. É exploratória no momento em que se familiarizou com o assunto e a realidade da organização pesquisada. É descritiva quando se procura descrever os depoimentos que dão sustentação às dimensões evidenciadas com base na análise da literatura: Dados Geográficos, Realizações/Desafios e Conceito principal de Conhecimento e GC.

Com vistas a alcançar o objetivo da pesquisa, foi inicialmente realizada uma revisão de literatura com a finalidade de aprofundar o contato com o tema do estudo: gestão do conhecimento. A partir da revisão, foi definida a utilização da abordagem qualitativa de pesquisa, entendida por Trivinõs (1987) como aquela capaz de analisar os aspectos implícitos no desenvolvimento das práticas de uma organização e a interação entre seus integrantes. Essa abordagem foi utilizada, pois ela possibilita explorar e entender o significado atribuído pelos indivíduos ou os grupos a um problema social (CRESWELL, 2010). Para planejamento e posterior execução da pesquisa, foram utilizadas as prescrições propostas por Creswell (2010) no que se refere à estratégia de investigação; aos procedimentos de coleta de dados; ao papel dos pesquisadores; aos procedimentos de registro de dados; à análise e interpretação dos dados; à confiabilidade, validade e generalidade ao relatório qualitativo.

Relativamente à estratégia de investigação, utilizou-se o estudo de caso. Na concepção de Yin (2010), o estudo de caso é uma investigação empírica que estuda um fenômeno contemporâneo em profundidade e em seu contexto de vida real, especialmente quando os limites entre o fenômeno e o contexto não são claramente evidentes. No sentido da pesquisa, o fenômeno (a gestão do conhecimento) é estudado em seu contexto de vida real (a organização pesquisada, seus processos, tecnologias e pessoas), procurando extrair inferências a partir de limites difusos entre o fenômeno e o contexto. Nesse sentido, a unidade de análise escolhida foi uma organização multinacional fabricante de máquinas e equipamentos elétricos, especificamente sua unidade de motores elétricos - a WEG. A escolha da WEG deu-se pelas seguintes razões:

- A empresa já tem áreas dedicadas à documentação do conhecimento organizacional desde 1968 (Centro de Treinamento), 1973 (Seção de Organização e Métodos, Seção de Tecnologia e Seção de Normalização) e 1980 (Biblioteca Central e Centro Tecnológico).

- A empresa, desde a sua fundação, incentivou a geração e o compartilhamento de conhecimentos, e sempre praticou o sistema de gestão participativa, envolvendo todos os níveis hierárquicos.

- A empresa sempre focou na qualificação e aperfeiçoamento de sua equipe e utilizou sistematicamente o job rotatio.

- A empresa sempre buscou e disseminou conhecimento externo.

Quanto aos procedimentos de coleta de dados, foi utilizada a entrevista semiestruturada (procedimento principal), associada à utilização de documentos e observação não participante (procedimentos complementares). Na entrevista, o investigador formula perguntas ao investigado com o propósito de obter dados que interessem à investigação (GIL, 2008). Utilizou-se da entrevista semiestruturada em que as perguntas são guiadas por um conjunto de pontos de interesse, explorados pelo investigador ao longo da entrevista (GIL, 2008). Para guiar a entrevista, utilizou-se um questionário elaborado por Peter Heisig, Professor da Escola de Negócios da Universidade de Leeds, na Inglaterra. A Quadro 2 sintetiza a estrutura do questionário utilizado no levantamento.

Quadro 2 - Elementos do Questionário do Levantamento.

\begin{tabular}{|l|l|}
\hline Dimensões & Questões levantadas \\
\hline A. Dados & Dados do entrevistado \\
Demográficos & $\begin{array}{l}\text { Dados da empresa } \\
\text { Dados do país } \\
\end{array}$ \\
& Dados do setor econômico \\
\hline
\end{tabular}




\begin{tabular}{|l|l|}
\hline \multirow{4}{*}{$\begin{array}{l}\text { B. Realizações e } \\
\text { Desafios }\end{array}$} & $\begin{array}{l}\text { Teoria: } \\
\text { De acordo com a sua percepção, qual o principal avanço em GC, no contexto da WEG? } \\
\text { Que pesquisas precisam ser empreendidas para contribuir com o entendimento, } \\
\text { avanços e implementação da GC na WEG? } \\
\text { Existe algum modelo teórico de GC que a WEG usa como referência? }\end{array}$ \\
\cline { 2 - 2 } & $\begin{array}{l}\text { Prática: } \\
\text { Qual o avanço prático em GC mais recente na WEG? } \\
\text { Quais são as dificuldades enfrentadas no dia a dia da WEG em relação à GC? } \\
\text { Quais as ações conduzidas pela WEG para tratar essas dificuldades? }\end{array}$ \\
\hline \multirow{5}{*}{$\begin{array}{l}\text { C. Conceito } \\
\text { principal: } \\
\text { Conhecimento e } \\
\text { GC }\end{array}$} & $\begin{array}{l}\text { Conhecimento: } \\
\text { O que a WEG entende por conhecimento? } \\
\text { Há necessidade de uniformizar o termo conhecimento na WEG? } \\
\text { Há necessidade de empreender pesquisas empíricas relacionadas ao conhecimento? }\end{array}$ \\
\cline { 2 - 2 } & $\begin{array}{l}\text { Gestão do Conhecimento: } \\
\text { O que a WEG entende por GC? }\end{array}$ \\
\hline
\end{tabular}

Fonte: Os autores (2013)

Foi entrevistado o gerente do Departamento de Pesquisa e Inovação Tecnológica da unidade de negócio estudada. As entrevistas foram realizadas na própria empresa em maio de 2012. O local das entrevistas foi o próprio Departamento de Pesquisa e Inovação Tecnológica da WEG, na cidade de Jaguará do Sul/SC.

A escolha do local foi de comum acordo entre os pesquisadores e o gerente entrevistado do departamento, uma vez que o local facilitaria o acesso à documentação e atividades centrais de tecnologia da empresa, pois corresponde ao centro de maior importância de PeD (Pesquisa e Desenvolvimento) da WEG, tanto na concepção de novas soluções quanto na organização das atividades de estudo e de conhecimento científico e tecnológico.

Inicialmente, foram explicados os objetivos básicos do estudo, de forma a contextualizar a entrevista e reduzir ruídos de comunicação durante ela.

Em relação ao papel dos pesquisadores, além de realizarem a entrevista, os pesquisadores contribuíram com o estudo por meio de observações realizadas na unidade de negócio estudada.

Para o registro dos dados do grupo focal, foram utilizados dois gravadores, de forma a proporcionar segurança no caso de falha de um dos equipamentos. Ainda foram utilizadas anotações, relativas às respostas e comentários durante o grupo focal, e também durante a recepção e despedida da empresa, enquanto não havia gravação.

A análise e a interpretação dos dados foram realizadas prioritariamente sobre os dados coletados no grupo focal. Os relatos gravados dos participantes foram transcritos e analisados por meio de análise de conteúdo, que corresponde a "um conjunto de técnicas de análise das comunicações que utiliza procedimentos sistemáticos e objetivos de descrição do conteúdo das mensagens" (BARDIN, 2002, p. 38). Para a análise do conteúdo, foram utilizados os passos propostos por Creswell (2010), resumidos no Quadro 3.

Quadro 3 - Passos para a análise do conteúdo das entrevistas

\begin{tabular}{|l|l|}
\hline \multicolumn{1}{|c|}{ Passos } & \multicolumn{1}{c|}{ O que foi feito } \\
\hline $\begin{array}{l}\text { Passo 1: organização do } \\
\text { material }\end{array}$ & $\begin{array}{l}\text { Transcrição das entrevistas na íntegra, incluindo, inclusive, perguntas que } \\
\text { foram alteradas em virtude do contexto específico das entrevistas. }\end{array}$ \\
\hline $\begin{array}{l}\text { Passo 2: leitura das } \\
\text { transcrições }\end{array}$ & $\begin{array}{l}\text { Leituras de todas as transcrições, procurando evidenciar padrões nas falas } \\
\text { dos entrevistados. }\end{array}$ \\
\hline $\begin{array}{l}\text { Passo 3: agrupamento do } \\
\text { material por temas }\end{array}$ & $\begin{array}{l}\text { As falas foram separadas por segmentos de texto específicos, levando em } \\
\text { consideração as dimensões evidenciadas na análise da literatura. }\end{array}$ \\
\hline $\begin{array}{l}\text { Passo 4: organização do } \\
\text { material codificado }\end{array}$ & $\begin{array}{l}\text { As dimensões contendo as falas agrupadas foram organizadas de modo a } \\
\text { montar uma sequência descritiva lógica. }\end{array}$ \\
\hline $\begin{array}{l}\text { Passo 5: descrição das } \\
\text { dimensões }\end{array}$ & $\begin{array}{l}\text { As dimensões, uma vez organizadas, foram descritas, buscando } \\
\text { interconectá-las, bem como exemplificá-las com as falas dos participantes. }\end{array}$ \\
\hline $\begin{array}{l}\text { Passo 6: interpretação e } \\
\text { extração de significado }\end{array}$ & $\begin{array}{l}\text { Os dados foram interpretados com base na literatura, assim como nas } \\
\text { observações e documentos analisados. }\end{array}$ \\
\hline
\end{tabular}

Fonte: Baseado em Creswell (2010) 
Jáem relaçãoà confiabilidade, validade generalidade, procurou-se utilizar estratégias adequadas ao contexto do estudo realizado. Para garantir a confiabilidade, utilizaram-se as recomendações de Yin (2010), sendo todos os procedimentos realizados ao longo da pesquisa registrados em documentos à parte, inclusive constando as considerações dos pesquisadores participantes do grupo focal, bem como dos dados oriundos de suas observações. Além disso, conforme mencionado, os relatos do grupo focal foram transcritos em documentos à parte, incluindo perguntas extras realizadas durante a reunião. Relativamente à validade, utilizou-se a estratégia de triangulação proposta por Creswell (2010). Assim, procurou-se associar às análises, além dos dados coletados por meio do grupo focal, dados com base na observação dos pesquisadores, bem como dados oriundos de documentos e informações disponíveis na Web. Já no que concerne à generalização, considera-se, de acordo com Yin (2010), que o presente estudo de caso não possibilita a generalização dos resultados, apenas pode fornecer uma contribuição empírica ao estudo do tema, que pode ser complementado por outros estudos semelhantes em método e realizados em diferentes contextos.

Finalmente, com relação ao relatório qualitativo, procurou-se demonstrar, com base na realidade estudada, as dimensões evidenciadas na literatura e abordadas na fundamentação teórica do presente artigo. No que diz respeito à estruturação, os dados são apresentados na seção a seguir de forma descritiva. Quando conveniente para os resultados, são apresentadas algumas falas dos entrevistados de forma a exemplificar a descrição realizada. Nesse sentido, a próxima seção apresenta e discute os resultados do estudo.

\section{APRESENTAÇÃO E ANÁLISE DOS RESULTADOS}

Esta seção apresenta a relação entre o histórico da organização e as ações relacionadas à GC na empresa WEG. Além disso, apresentam-se o resultado e análise dos dados coletados por meio do questionário exposto na seção anterior. Os dados foram coletados em maio de 2012, e o entrevistado foi o Gerente do Departamento de Pesquisa e Inovação Tecnológica da empresa em questão. Uma síntese dos resultados encontra-se no Quadro 5.

\subsection{Evolução da gestão do conhecimento na organização}

Este item descreve a relação entre o histórico da organização e as ações relacionadas à gestão do conhecimento, ou seja, o que foi feito e que contribuiu para o alcance da situação atual da GC na empresa.

O Quadro 4 sintetiza as principais ações relacionadas à GC.

Quadro 4 - A gestão do conhecimento na organização

\begin{tabular}{|l|l|}
\hline \multicolumn{1}{|c|}{ Passos } & \multicolumn{1}{|c|}{ Ações relacionadas à gestão do conhecimento } \\
\hline $\begin{array}{l}1961- \\
\text { Surgimento da } \\
\text { WEG }\end{array}$ & $\begin{array}{l}\text { - A Weg foi inaugurada oficialmente em 16 de setembro de 1961, data da instalação dos } \\
\text { primeiros equipamentos para a produção de motores elétricos. } \\
\text { o tripé então, a WEG - palavra que significa "caminho" em alemão - procurou agregar } \\
\text { compõem o seu nome. } \\
\text { - Já naqueles primórdios, a principal preocupação de seus diretores estava relacionada } \\
\text { com o aperfeiçoamento técnico e a qualificação de sua mão de obra. Com esse intuito, } \\
\text { uma constante na história da WEG, criou-se, já na fase embrionária, um plano hierárquico } \\
\text { de funções e responsabilidades, objetivando colocar a pessoa certa no lugar certo. }\end{array}$ \\
\hline $\begin{array}{l}1965-\text { Curso } \\
\text { de Reciclagem }\end{array}$ & $\begin{array}{l}\text { - Envolvendo todos os níveis hierárquicos, incluindo a diretoria, 65 cursos de organização, } \\
\text { de chefia e liderança, de controle de qualidade, básicos de português e matemática, de } \\
\text { produtividade industrial e o tradicional de métodos e tempos, entre outros. }\end{array}$ \\
\hline $\begin{array}{l}1968-\text { Criação } \\
\text { do “CentroWeg” }\end{array}$ & $\begin{array}{l}\text { - O centro de formação permitiria que a empresa planejasse sempre melhor a } \\
\text { diversificação e verticalização de novos produtos, e ampliasse consideravelmente a } \\
\text { política de formação de recursos humanos na área técnica, já que não havia, em Jaraguá } \\
\text { do Sul, no final dos anos 1960, qualquer reserva de mão de obra qualificada para atuar } \\
\text { no tipo de produto WEG. A empresa passaria a suprir-se de mão de obra qualificada, ao } \\
\text { mesmo tempo em que institucionalizava o processo de aperfeiçoamento da já existente. }\end{array}$ \\
\hline
\end{tabular}




\begin{tabular}{|c|c|}
\hline $\begin{array}{l}1968 \text { - Primeira } \\
\text { compra de } \\
\text { Tecnologia }\end{array}$ & $\begin{array}{l}\text { - Visita à Alemanha para conhecer e buscar tecnologia. } \\
\text { - Aquisição dos projetos do Doktor Braun. Sendo assim, Werner e outros técnicos e } \\
\text { engenheiros foram, muitas vezes, para a Alemanha, negociar e aprender com o Doktor } \\
\text { Ingenieur Braun. Ele também esteve várias vezes na WEG, para ministrar palestras e } \\
\text { cursos internos. } \\
\text { - Grande salto: do motor empírico Werner para o motor científico Braun. }\end{array}$ \\
\hline $\begin{array}{l}\text { Décadas } \\
\text { de } 60 \text { e } 70 \text { - } \\
\text { Implantação } \\
\text { de Modelos de } \\
\text { Gestão }\end{array}$ & 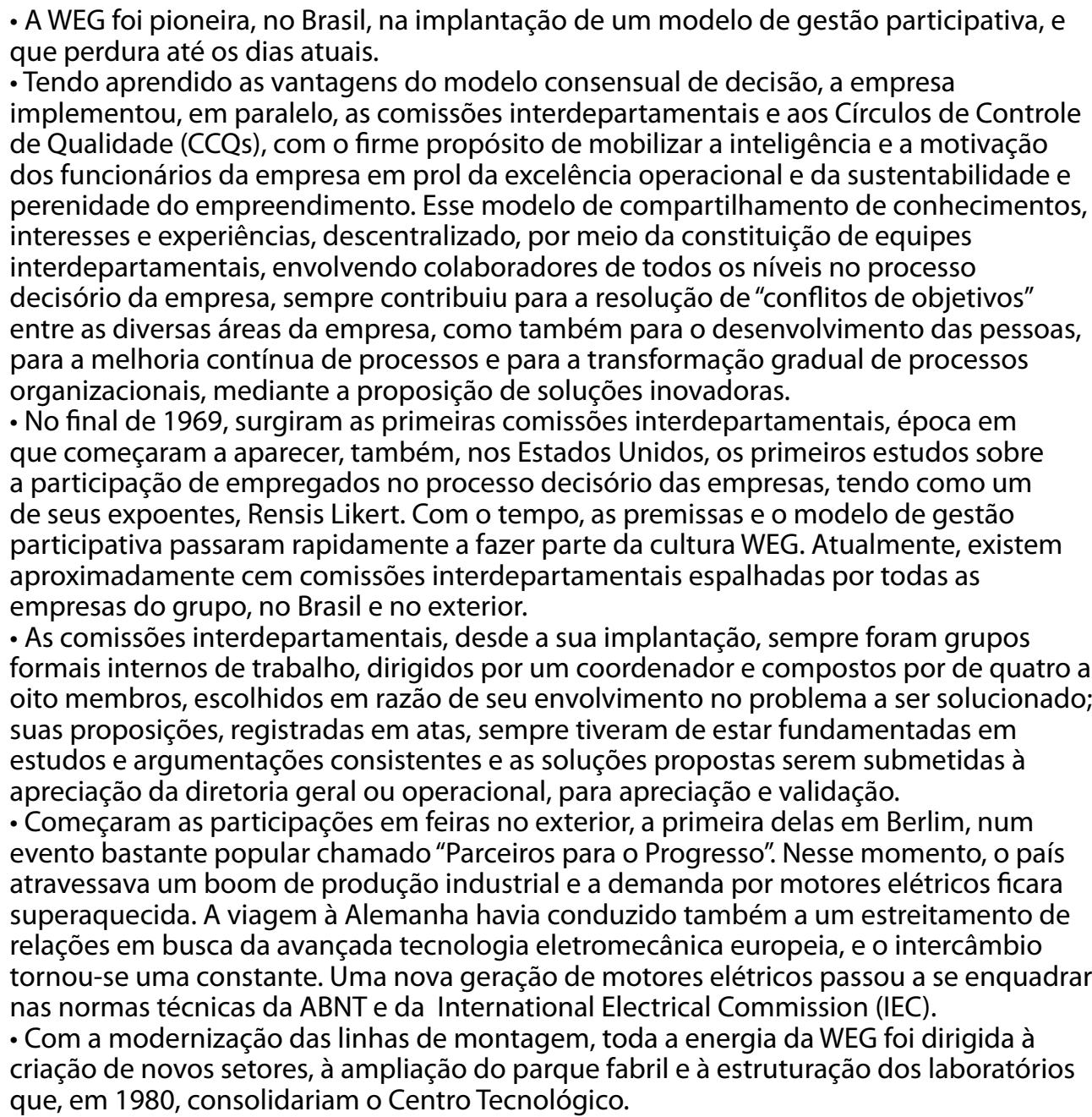 \\
\hline $\begin{array}{l}\text { O início da } \\
\text { Gestão do } \\
\text { Conhecimento }\end{array}$ & $\begin{array}{l}\text { - No modelo implantado na WEG, as redes de conhecimento que se estabeleceram } \\
\text { no interior das comissões e dos CCQs multiplicaram-se em novos conhecimentos e } \\
\text { concretizaram seus achados por meio de linha hierárquica, de forma sistemática, desde o } \\
\text { final da década de } 1960 \text {. O compartilhamento de conhecimento tácito de cada um (que } \\
\text { é obtido pela experiência individual) concretizou-se na esfera das comissões devido ao } \\
\text { fato de terem uma meta comum e, ao mesmo tempo, um clima propício de diálogo e à } \\
\text { manifestação das argumentações favoráveis e/ou contrárias à posição de cada um. } \\
\text { - A combinação do conhecimento de pessoas oriundas das diversas áreas funcionais da } \\
\text { empresa, integrada a um mesmo propósito, possibilitou às equipes enxergar o problema } \\
\text { de vários ângulos, com grandes chances de gerar um conhecimento sistêmico, condição } \\
\text { mais apropriada para atuar em ambientes complexos. Esse modelo permitiu não só a } \\
\text { transformação do conhecimento tácito em conhecimento organizacional, com 90\% das } \\
\text { soluções registradas e implementadas, mas também a incorporação de novas demandas } \\
\text { oriundas do ambiente interno e externo, repetindo o ciclo de novos conhecimentos. } \\
\text { A empresa, dessa forma, criou as condições e o contexto organizacional favoráveis à } \\
\text { geração e compartilhamento do conhecimento na WEG, sem hesitar em deixar sempre } \\
\text { claro seus valores e suas intenções estratégicas: "Não podemos deixar morrer o espírito } \\
\text { empreendedor em nossa organização". }\end{array}$ \\
\hline
\end{tabular}




\begin{tabular}{|l|l|}
\hline & - A empresa tem investido 3\% do seu faturamento em desenvolvimento tecnológico, \\
levando-a ao pleno reconhecimento pelo mercado, quanto à qualidade de seus produtos \\
e serviços, conquistando a liderança no mercado nacional e uma forte presença no \\
mercado internacional. Em 1992, conquistou o Prêmio Nacional de Qualidade. \\
• Com mais de 2.500 metas específicas, ano a ano, de produtividade e qualidade, \\
distribuídas em todos os departamentos da WEG, a empresa conquistou muitos títulos \\
de reconhecimento na área, como os prêmios Petrobras de Qualidade, Sesi de Qualidade \\
no Trabalho, Nacional de Qualidade de Vida, Finep de Inovação Tecnológica, Excelência \\
Empresarial (Fundação Getúlio Vargas), entre outros. \\
Gerenciando \\
suas \\
Tecnologias \\
absorver e fixar tecnologia, trinômio imprescindível a um autêntico desenvolvimento \\
industrial”. Implícitos a essas diretrizes, ficaram, então, gravados, permanentemente, os \\
seguintes princípios de gerenciamento dos ativos tecnológicos da WEG, aparentemente \\
rudimentares para a concepção atual de gestão do conhecimento:
\end{tabular}

Fonte: Os autores (2013)

\subsection{Respostas relacionadas a realizações, desafios e abordagens à Gestão do Conhecimento}

O maior avanço da WEG em GC consiste no uso de ferramentas de informática, para disseminar o conhecimento, tais como softwares desenvolvidos internamente, Sharepoint e TI como apoio à gestão. Entretanto, nota-se que, ainda que haja uma cultura arraigada em documentar a tecnologia própria, os maiores desafios consistem em transformar o conhecimento explícito em tácito. Há muita informação e documentação; contudo, a velocidade com que esse conhecimento é transformado em inovação tecnológica é inferior à da criação do próprio conhecimento, impactando no desenvolvimento de produtos, aperfeiçoamento de processo, marketing e inovação. Essa constatação de dificuldade vai ao encontro da WEG não ter um modelo formalizado de GC ou ciclo de vida do conhecimento. A empresa costuma enquadrar-se como "contra caso" tendo sempre como objetivo adequar modelos ou ferramentas às suas necessidades.

As medidas que estão sendo tomadas para o avanço prático dessas dificuldades consistem em utilizar ferramentas para disseminar conhecimento, organizar departamentos de pesquisa e inovação em grupos de competências para dar suporte à engenharia e à pesquisa, e almeja-se desenvolver a competência organizacional de inovação aberta.

No cotidiano, a WEG tem dificuldades em seu posicionamento no que se refere à GC em enfrentar o dilema atual de priorização, ou seja, há dúvida se se deve dominar o conhecimento sobre um assunto, ou apenas estar no nível de usuários da informação (nível superficial). Ainda há a dificuldade em como alcançar o comprometimento e a cooperação das pessoas quanto à busca do conhecimento para a empresa. Entretanto, a WEG é uma empresa aberta, tem processo de desenvolvimento de produto e inovação bem definidos, desenvolve a cultura de deixar o conhecimento disponível para todos na empresa e tem como prática valorizar aqueles que compartilham as informações como medidas de melhorias em relação à GC no dia a dia. A WEG procura reforçar os treinamentos, formar melhor os engenheiros novos, promover como política a liberdade dos departamentos em ter autonomia de solucionar problemas internos de GC, imperando o bom-senso, promovendo corporativamente reuniões todas as sextas-feiras para compartilhar o conhecimento de seus colaboradores e, ainda, CCQ dentro do expediente. 


\subsection{Resposta realizada sobre o conhecimento e Gestão do Conhecimento}

A WEG entende por conhecimento a definição de "como saber o que fazer, como fazer e saber avaliar as consequências desse fazer", derivado da aplicação da abordagem 5W2H. Enxerga-se a necessidade de alinhar a representatividade do termo conhecimento por políticas corporativas; contudo, a abordagem $5 \mathrm{~W} 2 \mathrm{H}$ é uniforme e bem entendida em todas as esferas da empresa, assim como o reconhecimento que conhecimento é fundamental ao processo de inovação. Há necessidade na empresa de empreender pesquisas empíricas relacionadas ao conhecimento; a WEG, culturalmente, parte do empirismo para adquirir novos conhecimentos, Essa realidade, entretanto, tem se alterado significativamente nos anos recentes, com ênfase no profundo entendimento dos fenômenos físicos relativos aos motores elétricos e no desenvolvimento de múltiplos projetos conceituais, fortemente amparados por técnicas de análise e simulação numéricas. A WEG entende a GC como a organização e planejamento do processo criativo e de aprendizado por toda a empresa, e gerir conhecimento dentro da empresa é torná-lo acessível a todos, motivando as pessoas para gerar mais conhecimento e aproveitá-lo para desenvolver a empresa, tendo como política forte de geração de novos conhecimentos por meio de pesquisa e desenvolvimento, investindo $2,6 \%$ nessas atividades (135 milhões em 2011).

\subsection{Respostas realizadas quanto às dimensões da Gestão do Conhecimento}

Atualmente a WEG tem considerado assuntos de muita importância ao desenvolvimento das GC ao que se referem às dimensões de Facilitadores Humanos e Sociais, Processos Organizacionais e Capacidades Organizacionais. Assuntos de nível importante ao desenvolvimento da GC se referem às dimensões de Resultado de Negócios, Facilitadores Tecnológicos e Estratégia Organizacional. As dimensões de Ambiente Organizacional e Sociedade e Economia têm atualmente nível de importância médio com relação às atividades da WEG à GC. Vale, contudo, destacar que em todas as dimensões abordadas relativas à GC, a empresa tem conhecimento, atividades, práticas e estratégias bem elaboradas e a compilação dos resultados a serem apresentados, com relação às dimensões da GC, está disponível no Quadro I.

\subsection{Dimensões da Gestão do Conhecimento consideradas muito importantes}

Em Facilitadores Humanos e Sociais, a empresa vê na formação do pessoal da produção e competência de pessoas a representação mais pertinente quanto a essa dimensão. Para tal, foca em treinamento dos empregados, pretendendo dobrar o número de empregos que há na atualidade (hoje 26 mil postos). Para isso, há o apoio da alta gestão, suportando essa mudança, verificada na formação de grupos multidisciplinares que agem como multiplicadores de pessoas e competências. Como ferramentas, vê a importância no seu programa de desenvolvimento; e busca, com ferramentas baseadas na WEB 2.0, focar na discussão, valorização de pessoas, e ouvir ideias de seus colaboradores. Todas essas necessidades estão previstas para serem concretizadas em seu plano organizacional em 2020 (Plano 2020).

Na dimensão Processos Organizacionais, a empresa prega um comprometimento parcial da produtividade para se atender às necessidades específicas dos clientes. Para tanto, busca o encurtamento das etapas do seu processo por automatização digital visando a um menor ciclo no desenvolvimento de seus produtos. Atua, com foco na GC, em inovações predominantemente tecnológicas e processo de produção Toyota como forma do atendimento do seu sistema de qualidade (Total Quality e just-in-time). Investe, como meta para 2015, em ferramentas de Enterprise Resource Planning (ERP), desenvolvidas pela SAP e outras ferramentas de qualidade japonesa e engenharia simultânea.

Capacidades Organizacionais são focadas atualmente na WEG em sua capacidade de customização dos seus produtos. Enxerga como necessidades, perante a GC, a sinergia organizacional em geração de ideias, além de estruturar e integrar as áreas de P\&D em todas as suas filiais, para assim criar centros de competência e elaboração de projetos por plataformas. Da mesma forma o desenvolvimento de seu ERP e de ferramentas de WEB 2.0 permitiu, como meta para 2020, a colaboração internacional do grupo.

\subsection{Dimensões da Gestão do Conhecimento consideradas importantes}

Diferenciação da empresa perante os concorrentes, lançamentos de novos produtos e menor lead-time são formas de como a empresa posiciona-se com relação à GC e a dimensão de Resultado 
de Negócios. A proposta para o Plano 2020 é audaciosa e visa como metas alcançar um orçamento de US\$20 bilhões (atual US\$ 6 bilhões) e dobrar sua área física, focando como ferramenta principal o desenvolvimento de seu ERP.

Em Facilitadores Tecnológicos, a WEG posiciona-se na integração corporativa e foca na competência de pessoas e tecnologias como facilitadores. Para isso, busca uma estrutura tecnológica atualizada, principalmente pela tecnologia de ponta em termos de máquinas automatizadas e nos seus ambientes de produção. Da mesma maneira, para o Plano 2020, compreendeno desenvolvimento de seu ERP para a integração corporativa e avaliação de ideias e colaboração internacional do grupo por ferramentas de WEB 2.0.

A WEG busca, pela dimensão de Estratégia Organizacional, a liderança tanto nacional como internacional (enfatizando seu crescimento na China e México), por meio de um portfólio amplo de produtos e pela diminuição das etapas de desenvolvimento de produtos, atividades auxiliadas pelo desenvolvimento do seu ERP. Constata assim, como necessidades formalizadas em seu Plano 2020, a sua atualização fabril, melhoria de sua produtividade e processos de produção, e, para a área de P\&D, autonomia local e estruturação das unidades no exterior.

\subsection{Dimensões da Gestão do Conhecimento consideradas de média importância}

Na dimensão de Ambiente Organizacional, a empresa trabalha em conjunto no desenvolvimento de seus produtos com seus fornecedores e interação diferenciada com seus clientes nesse desenvolvimento. Busca estratégias vinculadas do governo, tanto em áreas potenciais, como energias alternativas, quanto em órgãos de financiamento e representação em entidades públicas - hoje aWEG é o principal cliente da Financiadora de Estudos e Projetos (FINEP). Assim, a empresa busca, a partir de 2015, a automatização digital de fornecedores e clientes, fluxo de desenvolvimento formalizado com o cliente, principalmente pelo desenvolvimento de seu ERP. De maneira complementar, usufrui da Lei do Bem e institutos de fomento (FINEP e BNDS) para buscar novos projetos e atendimento de editais.

Por fim, no que diz respeito à dimensão Sociedade e Economia, a empresa considera historicamente fornecer alta qualidade pelo seu Centro de Treinamento WEG. Por via de cooperação com centros de estudos nacionais e internacionais, realiza pesquisas sempre orientadas com relação aos novos conhecimentos no mundo das máquinas elétricas. Procura manter os alunos nas universidades da região com incentivo de bolsas de $50 \%$ a futuros colaboradores e busca a criação de um polo de máquinas elétricas em um raio de $200 \mathrm{~km}$ na região onde se situa. Da mesma forma, com suas cooperações em diversas universidades, Brasil e em outros países, mantém laboratórios de máquinas elétricas por projetos de pesquisa de ponta. Para 2015, busca uma melhoria em realizar uma formatação sistêmica de sua memória organizacional. 
Quadro 5 - Perguntas e necessidade de pesquisa

\begin{tabular}{|c|c|c|c|c|c|c|c|c|}
\hline \multirow{3}{*}{$\begin{array}{c}\text { Perguntas / } \\
\text { Necessidade de } \\
\text { Pesquisa }\end{array}$} & \multicolumn{8}{|c|}{ Necessidades de pesquisa realcionada às dimensões de GC (Crescimento, Produtividade, Qualidade, Rentabilidade) } \\
\hline & $\begin{array}{c}\text { GC X Resultados de } \\
\text { negocios de }\end{array}$ & $\begin{array}{l}\text { GC X Facilitadores } \\
\text { humanos e sociais }\end{array}$ & $\begin{array}{l}\text { GC } \times \text { Facilitadores } \\
\text { tecnológicos }\end{array}$ & $\begin{array}{l}\text { Processsos de GC e } \\
\text { Processos } \\
\text { Organizacionais }\end{array}$ & $\begin{array}{c}\text { GC } \times \text { Capacidades } \\
\text { organizacionais }\end{array}$ & $\begin{array}{l}\text { GC } \times \text { Estratégia } \\
\text { organizacional }\end{array}$ & $\begin{array}{l}\text { GC X Ambiente } \\
\text { organizacional }\end{array}$ & $\begin{array}{c}\text { GC x Sociedade e } \\
\text { economia }\end{array}$ \\
\hline & 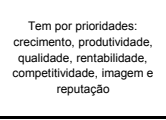 & 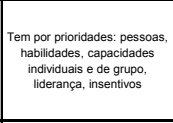 &  & 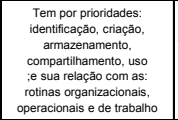 & 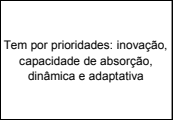 & 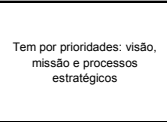 & 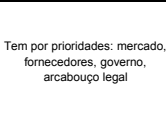 & 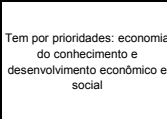 \\
\hline $\begin{array}{l}\text { Qual deveria ser } \\
\text { importancia da pesquisa } \\
\text { nessas áreas no futuro }\end{array}$ & Importante & Muito Importante & Importante & Muito Importante & Muito Importante & Importante & Médio & Médio \\
\hline $\begin{array}{l}\text { Por favor explique sua } \\
\text { posiçăo }\end{array}$ & 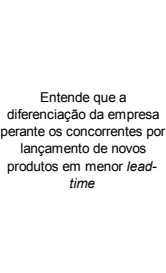 &  &  & 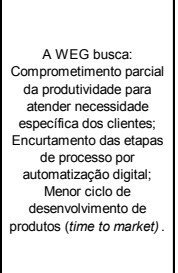 & $\begin{array}{l}\text { Busca se capacitar na } \\
\text { customizacáá de procoutos }\end{array}$ & 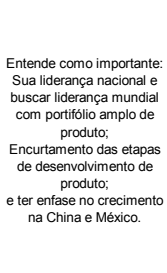 & 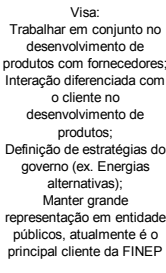 & 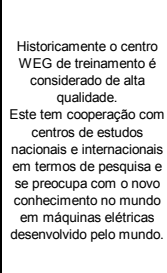 \\
\hline $\begin{array}{l}\text { Quais são os focos da } \\
\text { GC nessas } \\
\text { necessidades? }\end{array}$ & 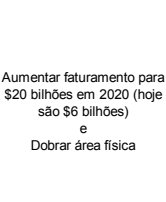 & 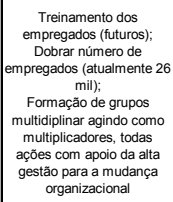 & 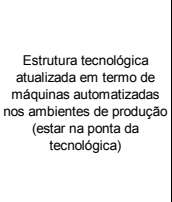 & 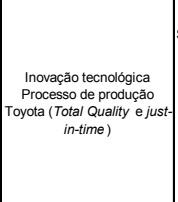 & 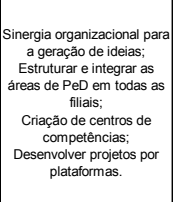 & 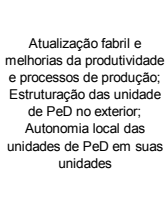 & 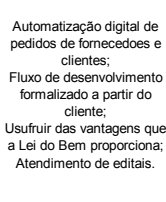 & 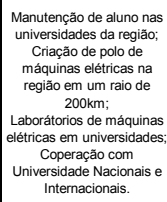 \\
\hline $\begin{array}{l}\text { Quais ferramentas são } \\
\text { mais viaveis nessas } \\
\text { necessidades? }\end{array}$ & $\begin{array}{l}\text { ERP (SAP) } \\
\text { Plano } 2020\end{array}$ & 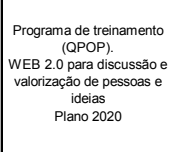 & 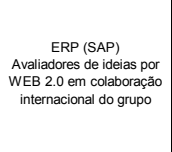 & 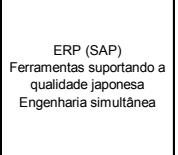 & 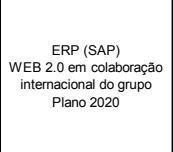 & ERP (SAP) & 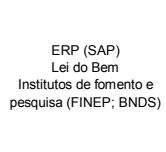 &  \\
\hline $\begin{array}{l}\text { Qual o prazo apropriado } \\
\text { para o cumprimento } \\
\text { dessa pesquisa? }\end{array}$ & 2020 & 2020 & 2020 & 2015 & 2020 & 2020 & 2015 & 2015 \\
\hline
\end{tabular}

Fonte: Os autores (2013)

\section{CONSIDERAÇÕES FINAIS}

A empresa WEG compreende a importância do conhecimento como fator de produção de valor. Dessa forma, realiza, em atividades já culturalmente incorporadas, formas de capturar, compartilhar e utilizar o conhecimento; contudo, tais atividades são realizadas majoritariamente de forma pontual e não sistemática.

Entretanto, ainda que haja a presença dos aceleradores para a GC, apoio da liderança, existência de processos, tecnologia, pessoas e cultura, não se consegue averiguar com esta pesquisa uma política deliberada de GC corporativa, isto é, um modelo de GC atuante de forma holística e integrada na corporação, para se configurar assim um Sistema de Gestão do Conhecimento.

Há, contudo, um compromisso sério em se desenhar processos orientados para os objetivos tangíveis da empresa, como a inovação, por exemplo. Porém, não se averigua nesse conjunto de seus processos e cultura interna o enquadramento completo nos moldes da GC, o que representa apenas parte do modelo da APO.

A WEG tem uma visão pragmática da realização de tarefas por meio do $5 \mathrm{~W} 2 \mathrm{H}$, que se traduz em uma política interna de reconhecimento dos principais fatores para desempenho das atividades empresariais. Todavia, ainda que a definição de gestão do conhecimento não seja empregada como tal na empresa, o termo está totalmente alinhado com a prática de $5 \mathrm{~W} 2 \mathrm{H}$ nela empregado. De fato, a definição de gestão do conhecimento, apesar de ter apenas o caráter prático e tangível de sua aplicação, reflete-se na postura de criação de novos conhecimentos na empresa, sobretudo vocacionalmente orientado por atividades de P\&D, conforme previsto pelo modelo da APO, que permita o desenvolvimento das capacidades e habilidades da WEG, traduzidos em crescimento, produtividade, qualidade, rentabilidade e inovação tecnológica constante.

Nota-se uma postura global da empresa reagindo às necessidades relativamente a todas as dimensões da GC por meio de um planejamento coorporativo de prazo médio, mostrando clareza de suas necessidades, foco de ações, ferramentas a serem aplicadas e prazo para atingir resultados. $O$ detalhamento desse planejamento ainda é impreciso; contudo, existe a necessidade de se averiguar se há conciliação do referido planejamento com um modelo estratégico de GC.

Pode-se afirmar que uma iniciativa de sucesso para a implementação de novas ações e ferramentas para o atendimento das dimensões de GC na WEG terá maior sucesso e efeito, na medida 
em que seja implementada com base no desenvolvimento de um projeto piloto. Nesse sentido, recomenda-se o desenvolvimento dessas iniciativas, a partir de um planejamento corporativo, baseado em um modelo estratégico de GC, que permita a implementação de um Programa de Gestão do Conhecimento em todas as áreas da empresa.

Sugere-se que tal área piloto seja o seu departamento P\&D que, por vocação e tradição, é o setor da empresa responsável em desenvolver novos conhecimentos, que se configuram como estratégicos para a WEG na inovação tecnológica. Além disso, o departamento de P\&D, atualmente, tem como desafio sua expansão e integração com seus outros escritórios nacionais e internacionais, de maneira que esse desenvolvimento piloto possa apresentar uma contribuição significativa para alcançar tal desafio. A partir dos aprendizados a serem adquiridos por meio dessa área piloto, o programa de GC poderia ser ampliado para outras áreas coorporativas da empresa.

No contexto atual, há uma forte correlação entre o atual desafio da WEG em relação à GC e à sua história de desenvolvimento tecnológico. De fato, atualmente a empresa depara-se com a necessidade de implementar um Programa de GC para se tornar uma empresa cada vez mais intensiva em conhecimento.

\title{
AN EMPIRICAL STUDY ABOUT KNOWLEDGE MANAGEMENT IN A MANUFACTURER COMPANY OF ELECTRICAL EQUIPMENT
}

\begin{abstract}
This article highlights the importance of continuous acquisition of new knowledge in the pursuit of competitiveness and innovation in organizations. In this context, it aims to characterize knowledge management in a large company in Jaraguá do Sul, in the northern region of the State of Santa Catarina. To collect data we used a questionnaire that is part of a global survey that has the purpose of conducting a review of the current state of the activities and progress of knowledge management in the context of academic research and organizational practice. The data revealed that, in the company researched, there are still challenges to be met and it also identified the need for future research in knowledge management.
\end{abstract}

Keywords: Electrical equipment. Technology. Knowledge management.

\section{REFERÊNCIAS}

BARDIN, L. Análise de conteúdo. Lisboa: Edições 70, 2002.

CAMPOS, C.; LANGRES, M.; LEMOS, V. A Gestão do Conhecimento na LG Sistemas: Um estudo de caso. In: CONGRESSO INTERNACIONAL DE CONHECIMENTO E INOVAÇÃO, 4., 2014. Anais... Loja, Equador: Universidad Técnica Particular de Loja, 2014.

CRESWELL, J. W. Projeto de Pesquisa: Métodos Qualitativo, Quantitativo e Misto. Porto Alegre: Artmed, 2010.

DAVENPORT, Thomas H.; PRUSAK, Laurence. Conhecimento empresarial: como as organizações gerenciam o seu capital intelectual. 12. ed. Rio de Janeiro: Campus, 2003.

DUBOIS, N; WILKERSON, T. Knowledge Management: Background Paper for the Development of a Knowledge Management Strategy for Public Health in Canada. Ontario: NCCMT, 2008. Disponível em: < http://www.nccmt.ca/pubs/KMpaper_EN.pdf>. Acesso em: 5 jun. 2015.

FREIRE, P. S. et al. Memória Organizacional e o seu papel na Gestão do Conhecimento. Revista de Ciência da Administração, Florianópolis, v. 14, n. 33, p. 41-51, ago. 2012.

Gil, A. Como elaborar projetos de pesquisa. São Paulo: Atlas, 2008.

KIMIZ, D. Knowledge Management in Theory and Practice. Boston: Elsevier, 2005.

NOGUEIRA, V. C. Gestão do Conhecimento: um estudo exploratório sobre as consequências provocadas pela perda das competências individuais segundo a percepção dos funcionários de TI. 2013. Dissertação (Mestrado) - Universidade Federal de Santa Catarina, Florianópolis, 2013.

NONAKA, I.; TAKEUCHI, I. Criação de conhecimento na empresa: como as empresas japonesas geram a dinâmica da inovação. Rio de Janeiro: Elsevier, 1997. 
NAIR, P.; PRAKASH, K. Knowledge management: facilitators' guide. Tokyo: Asian Productivity Organization, 2009.

STEIL, A. V. Estado da arte das definiç̧̃es de gestão do conhecimento e seus subsistemas. Florianópolis: Instituto Stela, 2007.

TRIVINÕS, A. N. S. Introdução à pesquisa em Ciências Sociais: a pesquisa qualitativa em educação. São Paulo: Atlas, 1987.

URIARTE Jr., Filemon A. Introduction to Knowledge Management. Jakarta: ASEAN Foundation, 2008.

YIN, R. K. Estudo de caso: Planejamento e Métodos. 4. ed. Porto Alegre: Bookman, 2010. 